Chirurgia (2019) 114: 384-391

No. 3, May - June

Copyright@ Celsius

http://dx.doi.org/10.21614/chirurgia.114.3.384

\title{
The Accuracy of the Preoperative Axillary Ultrasound Examination in Predicting the Status of the Sentinel Lymph Node Involvement in Patients with Infiltrating Breast Carcinoma
}

\author{
Orsolya Hankó-Bauer', Cristian Podoleanu², Rares Georgescu', Simona Stolnicu ${ }^{3}$
}

'University of Medicine, Pharmacy, Sciences and Technology of Targu Mures, Department of Surgery, Tg Mures, Mures ${ }^{2}$ University of Medicine, Pharmacy, Sciences and Technology of Targu Mures, Department of Internal Medicine, Tg Mures, Mures ${ }^{3}$ University of Medicine, Pharmacy, Sciences and Technology of Targu Mures, Department of Pathology, Tg Mures, Mures

Corresponding author:

Cristian Podoleanu, MD

Department of Internal Medicine,

University of Medicine and Pharmacy

of Tirgu Mures

38 Gheorghe Marinescu Street

Tirgu Mures 540139, Romania

E-mail: podoleanu@me.com

\section{Rezumat}

Acuratețea examinării ecografice preoperatorii a axilei în prezicerea statusului limfonodulului santinelă la pacientele cu carcinom mamar

Scopul studiului este de a determina acuratețea examinării ecografice preoperatorii a axilei în evaluarea statusului limfonodulului santinelă la pacientele cu carcinom mamar.

Materiale şi Rezultate: Din cele 54 paciente evaluate, examinarea ecografic a axilei a evidentiat limfonoduli vizibili în 35 de cazuri din care în 15 cazuri au fost prezente metastaze. În 19 cazuri, examinarea ecografică nu a evidențiat limfonoduli axilari vizibili, iar în 3 din aceste cazuri au fost prezente metastaze. Rezultatele studiului demonstrează faptul că nici diametrul maxim ( $\mathrm{p}=0.738$ test Fisher) şi nici raportul dintre axa longitudinală şi cea transversală $(p=0.728$ test Fisher) nu pot prezice statusul limfonodulului santinelă.

Concluzie: Examinarea ecografică a axilei la pacientele cu carcinom mamar nu poate prezice statusul limfonodulului santinelă.

Cuvinte cheie: limfonodul santinelă, examinare ecografică, carcinom mamar

Abstract

Background: we aimed to determine the accuracy of preoperative 
axillary ultrasound (US) in predicting the presence of sentinel lymph node (SLN) metastasis in breast cancer patients.

Methods and Results: out of 54 cases, visible nodes on US were identified in 35 cases of which, 15 had metastasis. In 19 cases no axillary lymph nodes were visible on US. Of these, only 3 had metastasis. Moreover, our results demonstrated that neither the maximum diameter $(\mathrm{p}=0.738$ Fisher exact test) nor the ratio between the longitudinal and transverse axes ( $\mathrm{p}=0.728$ Fisher exact test) can predict the positivity of the SLN.

Conclusion: US cannot predict the positivity of the SLN

Key words: sentinel lymph node, ultrasound examination, breast carcinoma

\section{Introduction}

The presence of axillary lymph node metas $^{-}$ tases is the most important prognostic factor in breast cancer, with an impact on both surgical and oncological therapeutic management $(1,2)$.

The locoregional progression of the disease plays an important role in determining the risk of recurrence and survival of breast cancer patients (3). Therefore, preoperative staging of patients with breast carcinoma involves assessment of the status of axillary lymph nodes.

In recent decades, staging according to axillary assessment has undergone a radical change from axillary lymph node dissection, associated with many complications and high morbidity, to sentinel lymph node (SLN) dissection (also called SLN biopsy in the international literature), a less invasive method that has become the international goldstandard in assessing the regional extension of the disease.

The role of axillary ultrasound examination in the staging of breast cancer was described in 1989 by Pamilo M et al. (4). They concluded that axillary ultrasound has a superior sensitivity to mammography and clinical palpation.Moreover, this examination guides the preoperative tru-cut biopsy of the node identified on ultrasound examination assuspicious of metastasis.

Currently, axillary ultrasound examination is routinely used in medical practice for preoperative identification of the axillary extension of breast cancer, which can be useful for determining which patients can benefit from SLN dissection, the eligibility criterion being the negative ultrasound and negative clinical axilla (5).

On the other hand, patients with suspicious lymph nodes identified clinically and/ or on ultrasound are eligible for the tru-cut biopsy of the suspicious nodes in order to confirm at microscopic examination the presence of metastasis. The axillary lymph nodes are suspected for metastasis if they display a round shape on ultrasound examination, have cortical focal thickening, lack fatty sinus and have aberrant peripheral vascularization (6).

The aim of this paper is to determine the accuracy of preoperative axillary ultrasound as a method of examination in predicting the presence of SLN metastasis in breast cancer patients, in order to be able to avoid unnecessary axillary surgery in selected patients with breast cancer.

\section{Material and Method}

\section{Inclusion Criteria}

We conducted a non-randomized prospective study in which we included 54 consecutive breast cancer patients confirmed by tru-cut biopsy, admitted to the Surgery Clinic (20152016). In all patients, SLN dissection was preceded by the ultrasound assessment of the axilla. 


\section{Exclusion Criteria}

Patients with radiologically confirmed metastatic axillary lymph nodes were excluded. In these cases, we performed ultrasound-guided tru-cut biopsy evaluation of the lymph node. If the presence of metastasis was not confirmedmicroscopically, the patient was subsequently subject to SLN dissection.

\section{Ultrasound Examination}

B-mode ultrasonography with a linear transducer of 8-12 MHz (Phlilips ClearVue 650) was performed by a single examiner skilled in mammary ultrasound examination with experience in the preoperative diagnosis of breast carcinoma (RG). The examination was performed identically in each patient included in the study. The patient lay in dorsal decubitus position with the hand placed under the head, and careful scanning of the axilla with the soft-tissue transducer was performed with the aim of identifying the lymph nodes. In each case, the number of lymph nodes visualized on ultrasound was recorded, along with details about longitudinal and transverse diameter, cortical thickness (diffuse thickening of the cortex), lymph node shape, fatty sinus disappearance, peripheral aberrant vasculari- zation. Figure 1 shows the preoperative ultrasound appearance of an axillary node without malignancy.

In every patient included in this study, SLN dissectionwas performed by the same surgeon experienced in breast cancer oncology (RG). On the day of the surgery, TC99 was injected periareolarly and/ or peritumorally in the nuclear medicine department followed by lymphoscintigraphy in order to visualize the axillary radioactive nodes. Intraoperatively, the radioactive node was detected by a gamma detection probe (Neoprobe 2000). Ten-second cumulative radioactivity of the lymph node (target count) was measured both in vivo and ex vivo. The residual radioactivity of the axilla was checked after removal of the sentinel node/nodes. In each case in which the residual activity did not exceed $10 \%$ of the cumulative activity of the last SLN, the surgeon considered that there were no other sentinel lymph nodes and the surgery was finished.

In each case, we recorded all USvLN (ultrasound visible but not suspicious for malignancy) lymph nodes and measured their diameter, ratio between the longitudinal (L) and transverse (T) $(\mathrm{L} / \mathrm{T})$ axes in order to determine the shape, cortical thickness, recorded the disappearance of the fatty sinus

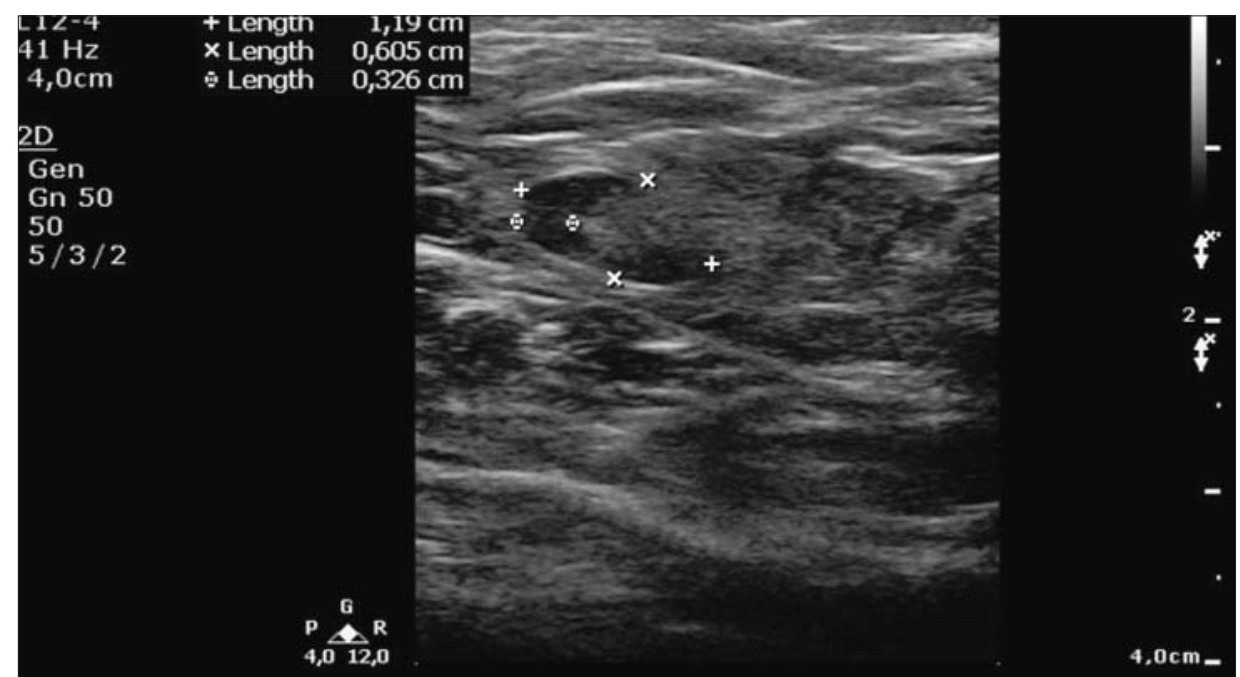

Figure 1. Preoperative ultrasound image of the axilla in a patient with confirmed breast carcinoma: an 11.9/6 mm diameter oval shape axillary lymph node, with a maximum cortical diameter of $32 \mathrm{~mm}$, free of malignancy was detected 
as well as the presence of aberrant peripheral vascularization.

We calculated the ratio between the longitudinal (L) and transverse $(\mathrm{T})(\mathrm{L} / \mathrm{T})$ axes of the nodes identified on ultrasound in order to determine their shape. If the ratio was $<2$, we considered it to have a round shape (one of the malignant ultrasound characteristics), whereas if the ratio was $>2$, we considered it to be oval (associated with benignity).

These data were subsequently correlated with the positivity or lack of positivity of the dissected SLN, as well as with the metastatic characteristics in SLN, if present.

\section{Morphological Examination}

The macroscopic and microscopic examination of the dissected axillary SLNs was performed by a single pathologist experienced in breast pathology (SS) using a single internal protocol in accordance with European and international guidelines by slicing each lymph node in fragment of $2 \mathrm{~mm}$ thickness and including all tissue fragments in paraffin blocks and then performing serial sections at every 250 microns interval. Microscopic appearance and evaluation of metastases in LNS as well as the size of metastasis and extracapsular extension were assessed according to pTNM (7).

\section{Statistical Analysis}

Statistical analysis of the data was performed using GraphPad Prism6 for Windows. Descriptive statistics were used for continuous variables. Comparison of SLN characteristics with ultrasound results was performed using Fisher exact test. The ROC curve (receiver operating characteristics curve) was performed using IMB SPSS Statistics 22 software. All tests were 2 -tailed and statistical significance was set atp $<0.05$.

\section{Results}

A total of 54 patients with invasive breast cancer confirmed on tru-cut biopsy were included in the study,with a mean age of

\section{$58.28 \pm 11.43$ years.}

A median of 2 radioactive lymph nodes/ patient (range: 1-7) were excised, of which a median of 0 (range: 0-3)were found to be metastatic on microscopic examination with a lymph node ratio (SLNR) of 0.21.

USvLN were identified in 35 cases. Of these, 15 had metastasis in the dissected SLNs (3 cases with micrometastases and 12 with macrometastases, of which 7 cases with extracapsular extension), and 20 without metastasis in the SLNs, confirmed by the histopathological examination.

In 19 cases no axillary lymph nodes were visible on preoperative ultrasound examination. Of these 19 cases, only 3 had metastasis in the sentinel lymph nodes on microscopic examination (1 micrometastasis and 2 macrometastases, of which 1 case with extracapsular extension), whereas in 16 cases, the sentinel lymph node was negative on microscopic examination.

Although the vast majority of negative cases on ultrasound did not have metastasis in the SLN, the preoperative ultrasound identification of the USvLN lymph nodes cannot predict the status of the sentinel node $(p=0.069$, Fisher exact test).

\section{Ultrasound Features}

The mean diameter of the nodes identified on preoperative ultrasound was $17.41 \pm 5.66 \mathrm{~mm}$. No fatty sinus disappearance or aberrant peripheral vascularization was identified.

Statistical analysis shows that neither the maximum diameter of the lymph nodes identified on ultrasound $(p=0.738$, Fisher exact test) nor the ratio between the longitudinal and transverse axes (namely, the shape of the node) $(p=0.728$, Fisher exact test) can predict the positivity of the SLN.

The median diameter of the thickened cortical nodes identified on ultrasound was 2 $\mathrm{mm}$ (range:1-4.5 mm). Of interest, in all the cases we examined, the cortical thickening was diffuse, not focal. Statistical analysis shows that cortical thickening above $2 \mathrm{~mm}$ is significantly associated with the positivity of the SLN ( $p=0.019$ Fisher exact test). 
Table 1 summarizes the monitored ultrasound parameters.

In our cases, preoperative axillary ultrasound displayed sensitivity (83\%) and a high negative predictive value (84\%), and specificity (44\%) and low positive predictive value $(42 \%)$. The accuracy of the method is $41 \%$.

The ROC curve was performed to determine the accuracy of preoperative ultrasound in the prediction of metastases in SLNs based on lymph node cortical thickness. The area under the curve is 0.727 , which shows a low accuracy (95\% Confidence Interval 0.573-0.882) (Fig. 2).

\section{Discussions}

Axillary ultrasound examination is an important investigation in the surgical treatment decision in breast cancer patients. Patients with negative ultrasound (in which no suspicious axillary lymph nodes are detected) benefit from SLN dissection, thus avoiding unnecessary axillary dissection, a major surgery with high morbidity (8). On the other hand, axillary ultrasound guides fine needle aspiration (FNA) or tru-cut biopsy of suspicious axillary lymph nodes for correct staging of the disease and helps to adjust the correct treatment (9).

A careful review of the literature reveals few articles that study the accuracy of preoperative ultrasound in predicting the positivity of the SLN. The working hypothesis of our study was to identify the ultrasound features in correlation with the presence or absence of metastases in SLN in order to avoid SLN biopsy in selected patients. Sentinel lymph node dissection surgery is a less invasive method

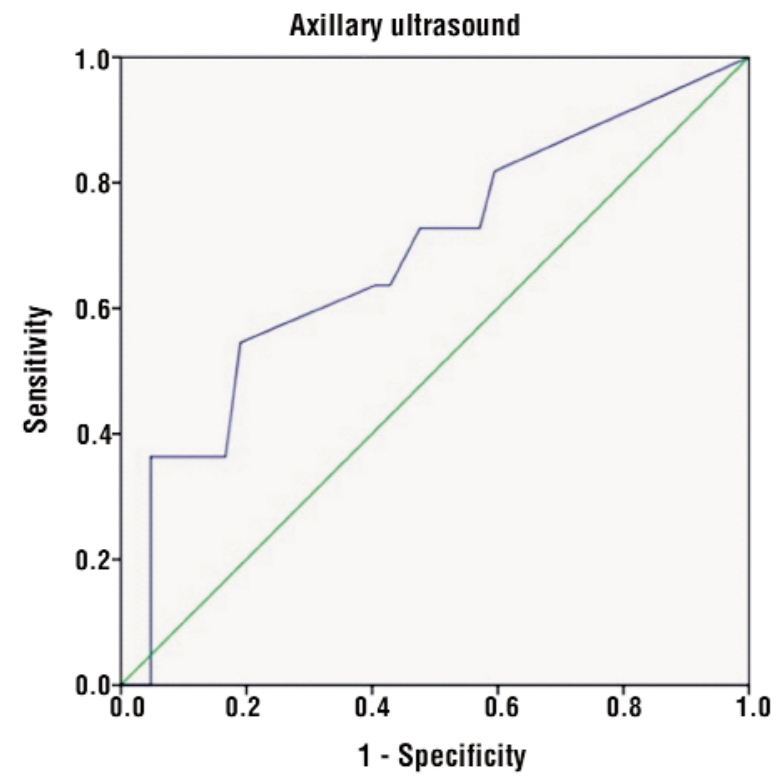

Figure 2. ROC - receiver operating characteristics curve represents the sensitivity and specificity of axillary ultrasound in the detection of metastatic axillary lymph nodes

than axillary lymph nodes dissection, but it also has several disadvantages for the patient, such as local complications of axillary rupture (development of axillary serums, hematoma, paresthesia due to nerve lesions), as well asa delayed initiation of the oncological treatment due to the fact that in most medical centers no intraoperative assessment (like examination using cytology, frozen section or molecular methods depending on the existing infrastructure in each medical center) of the SLN is performed, and the patient has to await the final pathological result, in case the positive SLN cannot be included in the Z0011 criteria

Table 1. Ultrasound features of the identified and examined SLNs (SNL: sentinel lymph node, T/ L ratio: ratio between longitudinal and transverse axis)

\begin{tabular}{|c|c|c|c|c|c|c|}
\hline \multirow[t]{2}{*}{ Ultrasound features } & & \multicolumn{2}{|c|}{ SLN + } & \multicolumn{2}{|c|}{ SLN- } & \multirow[t]{2}{*}{ p } \\
\hline & & $\mathbf{N}$ & $\%$ & $n$ & $\%$ & \\
\hline \multirow[t]{2}{*}{ Node maximum diameter } & $<17 \mathrm{~mm}$ & 6 & 17.14 & 10 & 28.57 & \multirow[t]{2}{*}{$p=0.738$} \\
\hline & $>17 \mathrm{~mm}$ & 8 & 22.86 & 10 & 28.57 & \\
\hline \multirow[t]{2}{*}{ L/T ratio (lymph node shape) } & $<2$ (round) & 5 & 14.29 & 10 & 28.57 & \multirow[t]{2}{*}{$p=0.728$} \\
\hline & $>2$ (oval) & 9 & 25.71 & 11 & 31.43 & \\
\hline \multirow[t]{2}{*}{ Cortical diameter } & $>2$ & 10 & 28.57 & 5 & 14.29 & \multirow[t]{2}{*}{$p=0.019$} \\
\hline & $<2$ & 5 & 14.29 & 15 & 42.86 & \\
\hline
\end{tabular}


and, consequently, she may be subjected to another surgery (3).

Studies on the sensitivity, specificity, and accuracy of axillary ultrasound have contradictory results in medical literature (Table 2).

In some papers, the authors demonstrated that ultrasound predicts axillary lymph node status.

Pessoa EC et al. studied the accuracy of axillary ultrasound in combination with FNA method versus clinical examination in metastatic lymph node detection (10). Logistic regression analysis showed no statistically significant correlation between clinical examination and pathologically positive axillae. However, in the axillae considered suspicious on ultrasonography, the risk of positive pathological findings increased 12.6-fold (10). The Receiver Operational Characteristics (ROC) analysis demonstrated that a cortical thickness of $2.75 \mathrm{~mm}$ corresponded to the highest sensitivity and specificity in predicting axillary metastasis (82.7, and $82.2 \%$, respectively).

In a study published in 2012, Abe $\mathrm{H}$ et al. discuss the utility of axillary ultrasound in the detection of axillary metastases (11). They conclude that axillary ultrasound is useful in the prediction of $\mathrm{pN} 2$ status, having a predictive positive value of $87 \%$.

Similar to the results of our study, Schwab demonstrated in 2010 that diffuse cortical thickening and complete loss of echo texture were the only features of ultrasound predicting malignancy, while palpation and mean size of the evaluated lymph nodes had no predictive value for malignancy (12).

More recently, Farshid (2015) demonstrated that axillary ultrasound had a sensitivity of $39.8 \%$, a $94.6 \%$ specificity, positive predictive value of $79.2 \%$, and a negative predictive value of $78.1 \%$ (13). But when combining axillary ultrasound examination with FNA, sensitivity was $76.5 \%$, specificity $90.9 \%$, positive predictive value $96.3 \%$, and negative predictive value $55.6 \%$. In women with negative axillary ultrasound, nodal metastasis was demonstrated in $21.7 \%, 86.8 \%$ of these having only $1-2$ positive nodes. In conclusion, according to Farchid, negative axillary ultrasound examination predicts negative or low nodal burden.

The article published in 2015 by Farrel TP et al. discusses the importance of preoperative axillary ultrasound in the Z0011 era in the evaluation of breast cancer patients. As a

Table 2. Comparison of our results with the results of similar articles in the literature

\begin{tabular}{|c|c|c|}
\hline Authors & No. cases & Results \\
\hline \multicolumn{3}{|c|}{ Ultrasound predicts axillary lymph node status } \\
\hline Pessoa EC, 2014 (10) & 100 & Sensibility: $82.7 \%$, Specificity: $82.2 \%$, Cortex: $2.75 \mathrm{~mm}$ \\
\hline Abe H, $2013(11)$ & 559 & PPV: $87 \%$ - in pN2 or higher \\
\hline Schwab FD, 2010 (12) & 51 & $\begin{array}{l}\text { Diffuse cortical thickening and complete loss of echo texture } \\
\text { were the only features on ultrasound predicting malignancy }\end{array}$ \\
\hline Farchid G, 2015 (13) & 303 & $\begin{array}{l}\text { Sensitivity: } 39.8 \% \text {, specificity: } 94.6 \% \text {, PPV: } 79.2 \% \text {, } \\
\text { NPV: } 78.1 \%\end{array}$ \\
\hline Farrell TP, 2015 (14) & 679 & Sensibility $86.2 \%$, specificity $100 \%$, PPV $100 \%$ NPV $71.9 \%$. \\
\hline Deurloo EE, 2003 (15) & 268 & Sensibility: $95 \%$, specificity: $44 \%$, with cortex $2.3 \mathrm{~mm}$ cut-off \\
\hline Van Berckelaer, 2016 (16) & 336 & $\begin{array}{l}\text { Sensibility: } 75 \% \text {, specificity: } 100 \% \text {, accuracy: } 92 \% \\
\text { (ultrasound + FNA) }\end{array}$ \\
\hline \multicolumn{3}{|c|}{ Ultrasound does not predict axillary lymph node status } \\
\hline Maartje C. van Rijk, 2005 (17) & 726 & Sensibility: $35 \%$, specificity: $82 \%$ \\
\hline Valente SA, $2012(18)$ & 244 & Sensibility: $27 \%$, specificity: $96 \%$ \\
\hline Bailey A, 2015 (19) & 249 & Sensibility: $7.4 \%$, specificity: $91.8 \%$, NPV: $78 \%$, FPR: $80 \%$ \\
\hline Our study & 54 & $\begin{array}{l}\text { Sensibility: } 84 \% \text {, specificity: } 44 \%, \mathrm{NPV}: 83 \% \text {, PPV: } 42 \% \text {, } \\
\text { accuracy: } 41 \% \text {, cortical thickness: } 2 \mathrm{~mm}\end{array}$ \\
\hline
\end{tabular}


result of the study which included 679 patients and SLN dissection in 169 of them, the authors concluded that preoperative axillary ultrasound remains essential in the axillary management of breast cancer, having a sensitivity of $86.2 \%, 100 \%$ specificity, $100 \%$ positive predictive value, and a negative predictive value of $71.9 \%$ (14).

E.E. Deurloo et al. investigated the possibilities of reducing the number of sentinel lymph node dissections using preoperative axillary ultrasound. The results of the study show that the cortical thickness is the most important ultrasound parameter in the prediction of axillary lymph node metastases. By setting the $2.3 \mathrm{~mm}$ cut-off of cortex thickness, a sensitivity of $95 \%$ and a specificity of $44 \%$ can be achieved (15).

A recently published article published by Van Berckelaer studied the possibility of discarding the dissection of the sentinel lymph node using the staging of the ultrasound and of the biopsy (FNA). The results confirm the working hypothesis, establishing the sensitivity of $75 \%, 100 \%$ specificity, and $92 \%$ accuracy of the method (16).

In some other papers, the authors demonstrated that ultrasound does not predict axillary lymph node status.

A study published in 2005 by Maartje C. van Rijk et al. analyzed the accuracy of axillary ultrasound in order to avoid dissection of the SLN in patients with non-palpable axillary metastases. The study concluded that the sensitivity of axillary ultrasonography was $35 \%$ and the specificity was $82 \%$, which can be improved by using FNA (17). Although axillary ultrasound itself cannot replace SLN dissection, it is useful for selecting patients who can benefit from this surgery (17).

Another study published in 2012 by Valente SA et al. investigated the accuracy of several imaging examinations(including ultrasound) in the prediction of axillary lymph node positivity and concluded that the specificity of the combined imaging methods may reach $100 \%$, but they are inappropriate methods in predicting the positivity of axillary metastases (18). Valente's study, however, refers to the accuracy of ultrasound in the prediction of axillary metastases after complete axillary dissection and not to the positivity of the SLN.

The study conducted by Bailey A et al. compared the results of preoperative ultrasound with pathological axillary status in the clinically negative axilla. The results showed a sensitivity of $7.4 \%$, a specificity of $91.8 \%$, a negative predictive value of $78 \%$, a false positive rate of $80 \%$. The study concluded that axillary ultrasound couldn't replace dissection of the SLN in clinically negative nodal patients, due to low sensitivity and the false positively elevated rate (19).

The results of our study show that dissection of the SLN cannot be omitted in favor of axillary ultrasound, as it has a sensitivity of $83 \%$ and a specificity of $44 \%$ in the detection of the metastatic SLN, the accuracy of the method being 41\% (Table 2). The high negative predictive value of the method (84\%) suggests the negativity of the SLN in cases in which axillary lymph nodes are not visibleon ultrasound.

Among all the ultrasound parameters that we have been recording in this study (diameter, $\mathrm{L} / \mathrm{T}$ ratio, shape, cortical thickness, disappearance of the fatty sinus, presence of aberrant peripheral vascularization), only the thickening of the cortical lymph node over $2 \mathrm{~mm}$ correlates significantly with the positivity of the SLN. This is in agreement with results of Pessoa, Schwab and Deurloo (10, 12, 15).

\section{Conclusions}

This is the first study in the Romanian literature to the best of our knowledge is assessing the accuracy of the preoperatory ultrasound in the prediction of the sentinel lymph node status in breast cancer to avoid sentinel lymph node dissection. According to our results, preoperative axillary ultrasound cannot predict the positivity of the SLN. However, in cases when the cortex of the lymph node is thicker than $2 \mathrm{~mm}$ we can expect with highly probability the presence of metastasis in the SLN. The limitation of this series consistent of the small number of cases. Larger number of 
cases and more studies are needed to achieve a substantial conclusion. However, based on the results of the present study, the dissection of SLN cannot be avoided in favor of only ultrasound examination for the staging of the axilla in patients with breast cancer.

\section{Acknowledgement}

We would like to thank to Adrian Naznean from the Foreign Language Department, University of Medicine and Pharmacy of Tirgu Mures, Romania for the careful translation of the manuscript.

\section{Author's Contributions}

OHB and SS wrote the manuscript, RG provided clinical and radiological data and $\mathrm{CP}$ performed statistical analysis.

\section{Conflicts of Interest and Source of Funding}

None reported for all authors.

\section{References}

1. Vinh-Hung V, Nguyen NP, Cserni G, Truong P, Woodward W, Verkooijen HM et al. Prognostic value of nodal ratios in nodepositive breast cancer: a compiled update. Future Oncol., 2009;5(10): 1585-603

2. Martin FT, O'Fearraigh C, Hanley C, Curran C, Sweeney KJ, Kerin MJ. The prognostic significance of nodal ratio on breast cancer recurrence and its potential for incorporation in a new prognostic index. Breast J. 2013;19(4):388-93

3. Giuliano AE, Ballman K, McCall L Beitsch P, Whitworth PW, Blumencranz Pet al. Locoregional Recurrence After Sentinel Lymph Node Dissection With or Without Axillary Dissection in Patients With Sentinel Lymph Node Metastases: Long-term Follow-up From the American College of Surgeons Oncology Group (Alliance) ACOSOG Z0011 Randomized Trial, Ann Surg. 2016 ;264(3):413-20.

4. Pamilo M, Soiva M, Lavast EM - Real-time ultrasound, axillary mammography, and clinical examination in the detection of axillary lymph node metastases in breast cancer patients. J Ultrasound Med. 1989;8(3):115-20.

5. Veronesi U1, Paganelli G, Viale G, Luini A, Zurrida S, Galimberti V et al. Sentinel-lymph-node biopsy as a staging procedure in breast cancer: update of a randomised controlled study. The Lancet Oncology. 2006;7(12) 983-990.

6. Dialani V, James DF, Slanetz P. J. A practical approach to imaging the axilla, Insights Imaging. 2015;6(2):217-29

7. AJCC (American Joint Committee on Cancer) Cancer Staging Manual, 8th edition, Amin MB, Edge SB, Greene FL et al. (Eds), Springer, Chicago 201.

8. Mills P, Sever A, Weeks J, Fish D, Jones S, Jones P.Axillary Ultrasound Assessment in Primary Breast Cancer: An Audit of 653 Cases, The Breast Journal. 2010;16(5):460-463

9. Diepstraten SC, Sever AR, Buckens CF, Veldhuis WB, van Dalen T, van den Bosch MA et al. Value of Preoperative Ultrasound-Guided Axillary Lymph Node Biopsy for Preventing Completion Axillary Lymph Node Dissection in Breast Cancer: A Systematic Review and Meta-Analysis; Annals of Surgical Oncology, Ann Surg Oncol. 2014; $21(1): 51-9$

10. Pessoa EC, Rodrigues JR, Pessoa CP, Véspoli HM, Uemura G Axillary lymph node aspiration guided by ultrasound is effective as a method of predicting lymph node involvement in patients with breast cancer?; Rev Bras Ginecol Obstet. 2014;36(3):118-23

11. Abe H, Schacht D, Sennett CA, Newstead GM, Schmidt RA. Utility of preoperative ultrasound for predicting pN2 or higher stage axillary lymph node involvement in patients with newly diagnosed breast cancer., AJR Am J Roentgenol. 2013;200(3):696-702.

12. Schwab FD, Burger H., Isenschmid M. Kuhn A, Mueller MD, Günthert AR. Suspicious axillary lymph nodes in patients with unremarkable imaging of the breast. Eur. J. Obstet. Gynecol. Reprod. Biol. 2010;150(1):88-91

13. Farchid G., Kollias J., Grantley GP: The clinical utility of assessment of the axilla in women with suspicious screen detected breast lesions in the post Z0011 era. Breast Cancer Res Treat. 2015; 151(2):347-55

14. Farrell TP, Adams NC, Stenson M, Carroll PA, Griffin M, Connolly EM. The Z0011 Trial: Is this the end of axillary ultrasound in the pre-operative assessment of breast cancer patients? Eur Radiol. 2015; 25(9):2682-7.

15. Deurloo EE, Tanis PJ, Gilhuijs KG Muller SH, Kröger R, Peterse JL. Reduction in the number of sentinel lymph node procedures by preoperative ultrasonography of the axilla in breast cancer, Eur $\mathrm{J}$ Cancer. 2003;39(8):1068-73

16. Van Berckelaer C, Huizing M, Van Goethem M, Vervaecke A, Papadimitriou K, Verslegers I. Preoperative ultrasound staging of the axilla make's peroperative examination of the sentinel node redundant in breast cancer: saving tissue, time and money, Eur $\mathrm{J}$ Obstet Gynecol Reprod Biol. 2016;206:164-171.

17. van Rijk MC, Deurloo EE, Nieweg OE, Gilhuijs KG, Peterse JL, Rutgers EJ et al. Ultrasonography and Fine-Needle Aspiration Cytology Can Spare Breast Cancer Patients Unnecessary Sentinel Lymph Node Biopsy; Ann Surg Oncol. 2006;13(1):31-5

18. Valente SA, Levine GM, Silverstein MJ, Rayhanabad JA, Weng-Grumley $J G$, Ji $L$ et al. Accuracy of predicting axillary lymph node positivity by physical examination, mammography, ultrasonography, and magnetic resonance imaging; Ann Surg Oncol. 2012;19(6):1825-30.

19. Bailey A, Layne G, Shahan C Zhang J, Wen S, Radis S et al. Comparison between Ultrasound and Pathologic Status of Axillary Lymph Nodes in Clinically Node-negative Breast Cancer Patients; Am Surg. 2015;81(9):865-9. 